\title{
VALORANDO LA COOPERACIÓN SUR-SUR. UN ESTUDIO COMPARADO DE LAS EXPERIENCIAS DE COLOMBIA Y MÉXICO EN EL PERIODO 2008-2019
}

\author{
ASSESSING SOUTH-SOUTH COOPERATION. THE \\ EXPERIENCES OF COLOMBIA AND MEXICO 2008-2019
}

\author{
ÉVALUER LA COOPÉRATION SUD-SUD. ANALYSE \\ COMPARÉE DES EXPÉRIENCES COLOMBIENNE ET \\ MEXICAINE AU COURS DE LA PÉRIODE 2008-2019
}

\author{
Analilia Huitrón Morales \\ Universidad Complutense de Madrid \\ ahuitron@ucm.es
}

\begin{abstract}
Resumen: Pese a que la cooperación Sur-Sur (css) es un fenómeno poco novedoso dado que sus antecedentes se remontan a más de setenta años, uno de sus principales desafíos es la escasa y poco confiable información acerca de su funcionamiento y efectos en el desarrollo. Por ello, este documento tiene el propósito de contribuir con la generación de evidencia sobre esta modalidad con una aproximación práctica en América Latina a partir del estudio de dos experiencias: Colombia y México. En este artículo se valora hasta dónde los elementos propios de la css se aplican en sus marcos normativos, legales y procesos de gestión, así como en el alcance de sus resultados.
\end{abstract}

Palabras clave: cooperación Sur-Sur, css; América Latina; Colombia;

\section{México.}

AвSTRACT: South-South Cooperation (SSC) is not a novel phenomenon given its background goes back more than seventy years. However, there is a lack of information about its operation and impact. This article aims to contribute to the literature by generating evidence on this modality from an empirical perspective based on the analysis of two cases: Colombia and Mexico. The research seeks to explain how far the theoretical approaches of Ssc may be 
applied to their normative, legal and practical process, as well as to the scope of results.

Keywords: South-South cooperation, ssc; Latin America; Colombia; Mexico.

\section{Traducción de Fionn Petch, CM Idiomas}

RÉsumÉ: Bien que la coopération Sud-Sud (CSS) n'ait rien d'un phénomène récent puisque ses origines remontent à plus de 70 ans, l'un de ses principaux écueils réside dans le manque d'informations fiables concernant tant son fonctionnement que son impact en matière de développement. Cet article entend donc contribuer à produire des faits en la matière, et ce à travers une approche pratique de l'Amérique latine à partir de deux études de cas: celui de la Colombie et celui du Mexique. On y évaluera dans quelle mesure les caractéristiques propres à la coopération Sud-Sud se reflètent dans ses cadres réglementaires et légaux, dans ses processus de gestion, ainsi que dans l'ampleur des résultats obtenus.

Mots clés: coopération Sud-Sud, CSS; Amérique latine; Colombie; Mexique.

Traducción de Ariel Elbaz, CM Idiomas

Fecha de recepción: febrero de 2020

Fecha de aceptación: octubre de 2020 


\section{INTRODUCCIÓN}

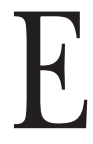

1 sistema internacional de cooperación para el desarrollo (SICD) ha experimentado cambios en su estructura, procesos y actores a raíz de un novedoso orden internacional donde los países de renta media (PRM), principalmente, han mostrado mayor protagonismo, dinamizando las relaciones económicas y políticas entre países en desarrollo. En este entorno, se presenta la cooperación Sur-Sur (css) como un fenómeno que puede resultar poco novedoso a la distancia dados sus antecedentes de más de setenta años y su creciente relevancia en los últimos quince. No obstante, hay una carencia de información en torno a su funcionamiento, resultados y efectos en el desarrollo y fortalecimiento de capacidades institucionales, así como respecto a los recursos (financieros y técnicos) que moviliza. La medición y valoración sobre la css se considera uno de los retos más relevantes para lograr exponer con evidencia sobre el valor agregado de esta modalidad en el SICD.

Además de la limitada evidencia en lo tocante a los resultados de la css, existen indicios que permiten pensar que el grado de la aplicación de los principios normativos proclamados como propios de la css puede no darse de manera plena en la práctica de esta modalidad, lo cual es un requisito esencial para su "efectividad". ${ }^{1}$ Por tanto, el artículo tiene como propósito contrastar hasta qué punto los planteamientos que sugiere la doctrina de la css se aplican en la realidad, desde el estudio empírico sobre su institucionalización, funcionamiento y posibles resultados de la política de cooperación de dos países oferentes de css: Colombia y México, generando con ello evidencia del valor añadido que aporta esta modali-

${ }^{1}$ BRICS y South-South Cooperation Research and Policy Centre (Articulação SUL), Paths for Developing South-South Cooperation Monitoring and Evaluation Systems, Río de Janeiro, BRICs Policy Center, 2017; Neissan Besharati, Carmel Rawhani y Ornela Garelli Rios, A Monitoring AndEvaluation Framework For South-South Cooperation, Johanesburgo, NeSt Africa-SAIIA, 2017. 
dad al SICD. A partir de este trabajo, se espera refrendar la hipótesis de que los países que proveen cooperación bajo esquemas Sur-Sur se refieren a la narrativa de la css como inspiradora de su práctica; no obstante, el grado en el que aplican esos elementos se observa poco consistente.

El documento se compone de cinco secciones. Después de esta introducción, la primera sección se enfoca en los aspectos metodológicos para el análisis empírico. La segunda y tercera se dedican al estudio de las experiencias de Colombia y México, respectivamente. La cuarta expone un análisis comparado en torno a la presencia de los elementos propios de la css en el funcionamiento y resultados de la política y práctica de la cooperación de las experiencias revisadas. Se concluye reconociendo las principales áreas de oportunidad de la política de css de ambos países para lograr una cooperación "efectiva".

\section{Cuestiones Metodológicas PARA EL ANÁlisis DE LOS ESTUDIOS DE CASO}

Para el cumplimiento del objetivo propuesto se hizo uso de una metodología de valoración en torno al funcionamiento y resultados de la css. Esta metodología, que contempla dos niveles de evaluación: i) nivel macro: normativo-institucional; y ii) nivel micro: proyectos de cooperación, permite contrastar los elementos doctrinales de las relaciones de colaboración entre países del Sur tanto en los marcos normativos de la política de cooperación como en la implementación de los proyectos. $^{2}$

Para el análisis que en este artículo se propone, sólo se utilizará el enfoque macro de la metodología señalada, orien-

${ }^{2}$ Para una revisión a profundidad de la metodología propuesta, así como la definición de los principios, dimensiones e indicadores utilizados se sugiere ver A. Huitrón, "Marco analítico para valorar la cooperación Sur-Sur. Una propuesta desde la academia”, El Trimestre Económico 350 (en prensa), 2021. 
tado a revisar los marcos jurídicos, normativos y mecanismos operativos sobre los que descansa la práctica de esta cooperación, reconociendo hasta qué punto aquellos elementos particulares de la css que se proclaman en la doctrina como deseables se encuentran en estos aspectos. Asimismo, el análisis pretende evaluar su efectividad institucional, examinando el alcance de sus resultados, los mecanismos de monitoreo y de rendición de cuentas.

La información para el análisis del nivel macro se recolecta, organiza y sistematiza mediante el uso de una matriz de valoración cualitativa que cuenta con 29 indicadores ${ }^{3}$ que se desagregan través de un método de descomposición deductiva a partir de cuatro de los principios que, según los propios países del Sur, deben guiar la política de css: ${ }^{4}$ implicación nacional; pertinencia; reciprocidad y horizontalidad. A estos principios, se añaden tres dimensiones de gestión y efectividad que tienen que ver con el efecto de la política pública: creación y fortalecimiento de capacidades; monitoreo y evaluación; así como rendición de cuentas y transparencia.

Así, para contrastar los principios doctrinales y analizar las dimensiones de efectividad mencionadas, se valorará con "sî" los casos en que el indicador se cumpla; se considera "no" cuando el indicador no aparece en los procesos y mecanismos revisados; y "parcialmente" se referirá a las ocasiones en que habría que hacer ajustes para que el principio y/o la dimensión correspondiente logre incorporarse de manera plena en

${ }^{3}$ Los indicadores se presentan con detalle en el cuadro 2, "Análisis comparado de la css de Colombia y México".

${ }^{4}$ Naciones Unidas, Documento final de Nairobi de la Conferencia de Alto Nivel de las Naciones Unidas sobre la Cooperación Sur-Sur, Resolución aprobada por la Asamblea General el 21 de diciembre de 2009, A/RES/64/222/, párr. 11; Naciones Unidas, Conference of Southern Providers South South Cooperation, Issues and Emerging Challenge, DESA/RIS, Nueva Delhi, 15-16 de abril de 2013, p. 2; N. Besharati, C. Rawhani y O. Garelli Rios, A Monitoring And Evaluation Framework For South-South Sudáfrica, Johanesburgo, NeSTAfrica-SAIIA, 2017,https:/ / saiia.org.za/research/a-monitoring-andevaluation-framework-for-south-south-cooperation; BRICS, op. cit. 
los procesos y mecanismos que guían la práctica de la css. Esto permitirá contrastar el nivel de aplicación de los principios de la css en la política correspondiente de México y Colombia.

Para obtener información cualitativa sobre la política de cooperación y los marcos normativos-institucional, así como mecanismos de gestión de las experiencias se realizó, en primer lugar, una revisión de literatura académica e institucional que estudia el contexto y los documentos oficiales de cada experiencia analizada; en un segundo momento, durante las estancias de investigación en cada uno de los casos estudiados se hicieron entrevistas semiestructuradas con personas implicadas en la gestión, aplicación e investigación de la política de cooperación. Se entrevistó durante 2015 y 2016 a 30 personas: responsables de la coordinación de la cooperación en cada una de las agencias de cooperación de los países seleccionados; sociedad civil; centros universitarios y académicos; dependencias gubernamentales y entidades locales. Esta evidencia cualitativa enriquece el análisis gracias a que se pudo contar con la perspectiva de las personas que, de primera mano, están vinculadas con la política de cooperación.

En cuanto a la selección de los casos de estudio: Colombia y México, tal elección responde a que ambos países pertenecen al grupo de países de renta media con mayor relevancia en América Latina, posicionándose en el último lustro como actores relevantes en sidc, no sólo como receptores, sino cada vez más como oferentes. Además de este papel dual, son países que han avanzado constantemente en sus procesos de institucionalización, gestión y medición de la cooperación internacional que reciben y ofrecen, fortaleciendo otras experiencias en la región.

En los últimos años, Colombia se ha posicionado como uno de los cinco países de la región con mayor número de iniciativas de oferta de cooperación. ${ }^{5}$ Además de realizar es-

${ }^{5}$ Secretaría General Iberoamericana, SEgIB, Informe de Cooperación Sur-Sur en Iberoamérica, Madrid, 2007-2017. 
fuerzos relevantes para ordenar, registrar, sistematizar e, incluso, valorar sus acciones de cooperación, contando con información pública sobre sus proyectos y diseñando una metodología de "agregación de valor" con la cual cuantificar los recursos financieros destinadas a la css, también evalúa la contribución de la cooperación colombiana al desarrollo y su alineación con los Objetivos de Desarrollo Sostenible (oDs).

México, por su parte, es quizás el país en la región que más avances ha tenido en la configuración de una arquitectura institucional de su política de cooperación, dado que cuenta con una Ley de Cooperación Internacional para el Desarrollo (LCID $)^{6}$ y con la Agencia Mexicana de Cooperación Internacional para el Desarrollo (Amexcid). Es asimismo el país que ha dedicado esfuerzos para erigir un sistema de registro y cuantificación de su cooperación internacional a nivel nacional.

\section{Colombia}

Se ha posicionado en los últimos años como uno de los principales países cooperantes de la región latinoamericana, de acuerdo con los informes de la Segib. Asimismo, ha intentado focalizar y orientar su cooperación internacional de manera estratégica, marcando una "hoja de ruta" para el periodo 2015-2018, identificando áreas y sectores prioritarios. Además, es uno de los países de la región que ha hecho esfuerzos relevantes para ordenar, registrar, sistematizar e, incluso, valorar las acciones de cooperación. Cuenta con información pública sobre sus proyectos de cooperación mediante "datos abiertos" y recientemente diseñó el "Modelo de Cuantificación y Agregación de Valor" (MCAv), con el que se espera no sólo contar con información cuantitativa de los recursos fi-

${ }^{6}$ Ley de Cooperación Internacional para el Desarrollo, Diario Oficial de la Federación, 6 de abril de 2011, última reforma, 6 de noviembre de 2020, http://www.diputados.gob.mx/LeyesBiblio/pdf/LCID_061120.pdf 
nancieros y técnicos que provee, sino también tener conocimiento sobre la aportación de su política de cooperación al desarrollo. En 2013, Colombia inició formalmente las negociaciones para entrar a la OCDE. En 2020, tras un arduo proceso de reformas y ajustes en sus políticas de regulación, legislación, transparencia, entre otras, se convirtió formalmente en el miembro 37 de esta organización, uniéndose a los dos únicos países latinoamericanos ya miembros: México y Chile.

En tal contexto, la política de cooperación de Colombia ha ido evolucionando y reforzándose para adoptar una estrategia que le permita profesionalizar su capacidad como oferente de cooperación para "hacer una cooperación eficiente". ${ }^{7}$

Marco institucional, organizativo y normativo de la cooperación de Colombia

Con la creación de la Agencia Presidencia de Cooperación Internacional de Colombia (APC-Colombia) en 2011, y a través del Decreto 4152, se define con mayor claridad la división de trabajo en materia de cooperación entre la Agencia y la cancillería; en éste se estipula que la primera es responsable de la coordinación y ejecución de la cooperación, es decir, el "brazo técnico" de la política, mientras que la segunda es responsable de definir las prioridades y líneas de acción de la cooperación.

La APC-Colombia está liderada por un director general y coordinada por un consejo directivo formado por siete miembros: tres asignados por la Presidencia y cuatro más representantes de los ministerios de Relaciones Exteriores y de Defensa, así como del Departamento Administrativo de la Presidencia de la República (Dapre) y del Departamento Nacional de Pla-

7 Ángela Ospina de Nicholls, directora de la APC-Colombia, en el marco del Foro de la Oficina de las Naciones Unidas para la Cooperación Sur-Sur (unOssc), Estambul, Turquía, diciembre de 2019. 
neación (DNP). A su vez cuenta con cuatro direcciones: Administrativa y Financiera, Coordinación Interinstitucional, Demanda y Oferta. Esta última Dirección está a cargo de identificar, formular y coordinar la implementación y monitoreo de los proyectos de oferta de cooperación, así como de establecer las alianzas estratégicas con países a nivel bilateral y regional, a través de la modalidad de css y triangular.

A esta estructura se suma el Fondo de Cooperación Internacional (Focai), que se creó exclusivamente para financiar los programas, proyectos y acciones de cooperación horizontal que Colombia destina a los países de similar o menor nivel de desarrollo. Este Fondo, cuyo antecedente es el Fondo de Cooperación para Centroamérica y el Caribe establecido en 1982, "funcionaría como una cuenta especial, sin personería jurídica, con el objeto de apoyar las acciones de cooperación técnica y financiera no reembolsable y de asistencia internacional que Colombia realice con otros países de desarrollo". 8 El Focai recibe los recursos fundamentalmente de tres fuentes: presupuesto general de la nación, donaciones bilaterales y multilaterales al país. Estos fondos cubrirán los gastos que se generen debido a la ejecución de iniciativas de cooperación técnica y financiera, donaciones, apoyo en prevención de desastres y crisis humanitaritas, naturales y/o económicas. $^{9}$

${ }^{8}$ Presidencia de la República, Decreto núm. 2467 de 2005, de 21 de julio de 2005, por el cual se fusiona la Agencia Colombiana de Cooperación Internacional, ACcI, a la Red de Solidaridad Social, Rss, y se dictan otras disposiciones, https://www.cancilleria.gov.co/sites/default/files/ Normograma/docs/decreto_2467_2005.htm. En lo relativo al Focai, también se sugiere ver el documento Agencia Presidencial de Cooperación Internacional de Colombia (APC), Acuerdo núm. 04 de 7 de marzo de 2012, por el cual se adopta el reglamento del Fondo de Cooperación y Asistencia Internacional, Focai, Colombia, https://www.apccolombia. gov.co/sites/default/files/archivos_usuario/normograma_2017/acu04mar7_2012_1.pdf

${ }^{9}$ Ley 318 de 2 de septiembre de 1996, Congreso de Colombia, Diario Oficial No. 42.884, 24 de septiembre de 1996, por la cual se establecen mecanismos para el manejo de los recursos financieros destinados al cum- 
En cuanto al marco normativo, si bien la cooperación colombiana no cuenta con una Ley que sustente jurídicamente su quehacer, desde $2004^{10}$ se han diseñado tres Estrategias Nacionales de Cooperación Internacional: 2004-2006; 20072010; 2012-2014, además de la Hoja de Ruta de la Cooperación Internacional 2015-2018, con el propósito de definir las líneas acción que deben orientar la cooperación internacional que recibe y ofrece el país.

En 2015 se elabora la "Hoja de Ruta de la Cooperación Internacional 2015-2018", ${ }^{11}$ documento aprobado por el Consejo Directivo en mayo de 2015 y que se sustenta en el Plan Nacional de Desarrollo 2014-2018 "Todos por un Nuevo País: Paz, Equidad y Educación”. Esta Hoja de Ruta tiene dos objetivos: a) focalizar y dinamizar la cooperación que recibe el país y b) compartir conocimiento de valor con países de desarrollo. Para cumplir este segundo objetivo, la APC-Colombia cuenta con cuatro mecanismos de acción:

i) Estrategias regionales. Incluyen la articulación de las demandas de varios países en una región a las que la APC-Colombia pretende dar respuestas, mediante alianzas estratégicas y

plimiento de los compromisos financieros internacionales, se crea la Agencia Colombiana de Cooperación Internacional y se dictan otras disposiciones para el fomento de la cooperación internacional. Véase http:/ / www.secretariasenado.gov.co/senado/basedoc/ley_0318_1996.html

${ }^{10}$ En 2004 se inicia un proceso de diálogo entre el gobierno de Colombia, la sociedad civil y la comunidad internacional para diseñar la primera Estrategia de Cooperación Internacional para Colombia 2004-2006, una guía que permitió coordinar, armonizar y alinear la cooperación que recibía este país. La Estrategia tuvo su origen en el Proceso de Londres-Cartagena, 2003. Véase Programa de Naciones Unidas para el Desarrollo, PNud, De Londres a Cartagena y a Bogotá. Estrategia de Cooperación Internacional para Colombia, Bogotá, PNUD, 2007, http:// www.acnur.org/t3/fileadmin/Documentos/Publicaciones/2008/6031. pdf?view $=1$

${ }^{11}$ La "Hoja de Ruta" se puede consultar en el siguiente enlace del Gobierno de Colombia: https://www.apccolombia.gov.co/pagina/enque-consiste-la-hoja-de-ruta-de-cooperacion-internacional-de-colombia 
la cooperación triangular. Cuatro son las estrategias regionales prioritarias para la APC-Colombia: Euroasia, África, Europa del Este y el Caribe. ${ }^{12}$

ii) Programas bilaterales de cooperación. Son el "ámbito natural” sobre los que Colombia despliega su css a través de convenios marco de cooperación.

iii) Alianzas estratégicas con diversos actores. Las alianzas estratégicas son canales a través de los cuales la APC-Colombia establece un acuerdo "gana-gana" con un socio público, privado, sociedad civil y/o academia con el fin de potenciar el intercambio de aprendizajes y la participación en la cooperación de diferentes actores.

iv) Apoyo a los procesos de integración regional. La APC-Colombia promueve iniciativas de css y la triangulación en plataformas de interacción regional como Segib, Alianza del Pacífico y Focalae (Fondo de Cooperación América Latina-Asia del Este). ${ }^{13}$

\section{Funcionamiento de la cSS de Colombia}

Con el fin de someter a análisis la operatividad de la cooperación colombiana, este apartado se centrará en conocer cómo se ejecuta la política de cooperación en cuatro etapas: planeación, negociación, monitoreo y evaluación.

12 Cabe mencionar que si bien no lo destaca la Hoja de Ruta 20152018, Colombia cuenta con otra estrategia regional de cooperación en temas de seguridad, liderada por el Ministerio de Relaciones Exteriores (no por APC-Colombia). Véase: https://www.cancilleria.gov.co/interna tional/politics/cooperation/south

13 APC-Colombia, Presentación Rendición de Cuentas, APC-Colombia 2015, http:/ /www.apccolombia.gov.co/sites/default/files/archivos_usuari o/2016/presentacion-rendicion-de-cuentas-apc-colombia-2015.pdf 


\section{Planeación y negociación}

La APC-Colombia es el órgano coordinador de la cooperación colombiana encargado de priorizar, planificar y formular los proyectos y actividades de cooperación con los países socios a través, principalmente, de las Comisiones Mixtas (Comixtas), presididas por la Dirección de Cooperación Internacional del Ministerio de Relaciones Exteriores en conjunto con la parte técnica de la APC-Colombia, y en ellas se acuerdan los proyectos y acciones que se llevaran a cabo entre las partes. Bajo este mecanismo, los países receptores presentan las demandas de cooperación alineadas a sus necesidades nacionales de desarrollo, que revisan las entidades ejecutoras de Colombia, las cuales señalan las capacidades y experiencias que se tienen y que son susceptibles de ser compartidas con el país socio a fin de dar respuesta a la demanda previamente solicitada. ${ }^{14}$ No obstante, por ahora, la APC-Colombia no cuenta

14 Cabe mencionar que este proceso no siempre ha sido así. En un principio, el papel de las entidades ejecutoras en el proceso de planeación y negociación de las iniciativas era opacada por las funciones exclusivas de las instituciones encargadas de la coordinación y proposición exterior, es decir del Ministerio de Relaciones Exteriores, debido al escaso desarrollo institucional en lo que a la cooperación se refiere (Pablo Uribe, "Colombia: Hitos y tendencias como nuevo donante", en Guillermo Santander Campos (coord.), Nuevos Donantes y Cooperación Sur-Sur: estudios de caso, Madrid, Universidad Complutense de Madrid, Instituto Complutense de Estudios Internacionales, 2011, pp. 63-87). Guáqueta, al respecto, aludía a que esto se debía a una falta de coordinación interinstitucional, dado que cada Ministerio y/o entidades de gobierno tiene oficinas especializadas en actividades de cooperación que muchas veces se ciñen a ciertas especificaciones de la cooperación técnica sin atender a una mayor coordinación con otros canales institucionales, como es el Ministerio de Exteriores y/o Acción Social, en ese entonces el "brazo técnico" de la cooperación (A. Guáqueta, "La cooperación técnica en Colombia como una herramienta estratégica de política exterior", $R e-$ vista Colombia Internacional, núm. 30, 1995, pp. 3-15, https:/ / colombiainter nacional.uniandes.edu.co/view.php/208/1.php). Esta multiplicidad de vías a través de las cuales se pueden establecer canales para la cooperación aún adolece de madurez institucional y de mayor coordinación, lo cual 
con un proceso estandarizado y/o sistematizado en lo relativo a la planificación y priorización de los proyectos de cooperación.

Por su parte, con las regiones de Asia, África y Europa del Este, el establecimiento de las relaciones de cooperación no descansa en una instancia de negociación como las Comixtas, sino en reuniones bilaterales y sesiones de trabajo sin plazos determinados, así como bajo esquemas de comunicación ad-hoc. La estructura institucional de la APC-Colombia no siempre encuentra una institución homologa en el país socio y, en ocasiones, carece de canales y protocolos, lo que hace el proceso más específico y, a veces, complejo, tomando un ritmo más pausado que el que se pueda desarrollar con los países de América Latina.

Para hacer más eficiente este proceso, la APC-Colombia ha elaborado una "caja de herramientas" que ayuda a la gestión de las iniciativas de cooperación. Estas herramientas, diseñadas en 2016 con la colaboración del Programa de Naciones Unidas para el Desarrollo (PNUD), tienen el objetivo de facilitar la operativización de cooperación colombiana, haciendo que desde el diseño hasta la conclusión de los proyectos, y el intercambio de conocimiento y experiencias sea lo más eficiente posible, y que durante el proceso se cuente con elementos estandarizados que permitan el seguimiento y la evaluación de la cooperación que se ofrece. Estas herramientas permiten verificar que los proyectos se encuentran alineados con los planes nacionales de desarrollo y sectoriales tanto de Colombia como de los países socios, así como con los ods.

\section{Monitoreo y evaluación}

Una vez que los proyectos se encuentran definidos y aprobados, corresponde activar los procesos de seguimiento y la

dificulta el diseño de una política de cooperación unificada. No obstante, se ha conseguido un proceso más coordinado y participativo. 
evaluación. En el caso de Colombia estos procesos han sido una pieza clave del fortalecimiento institucional que se ha impulsado en los últimos años, existiendo actualmente herramientas y procedimientos que los facilitan.

En el plano bilateral, una vez más se alude a las Comixtas, que establecen mecanismos de seguimiento y revisión conjunta. En las Comixtas se cuenta con mecanismos de seguimiento en reuniones trimestrales o semestrales, según se determinen los plazos entre las partes, en las que se examina el nivel de ejecución de los programas, sus avances y dificultades. ${ }^{15}$

Por su parte, el seguimiento y monitoreo se vuelve más disperso y complejo en los proyectos con regiones como África, Asia o Medio Oriente. Actualmente (2019) no hay procesos ni mecanismos que permitan el seguimiento con estos países socios, aunque desde 2016 se han realizado esfuerzos piloto para determinar la mejor manera de que esto sea posible. Esto supone uno de los desafíos más relevantes que la APC-Colombia ha de solventar si desea fortalecer su cooperación e incrementar su eficiencia hacia otras regiones.

En cuanto a la evaluación, si bien la APC-Colombia ha sido innovadora al diseñar y poner a prueba el Modelo de Cuantificación y Agregación de Valor (MCAv) para dar seguimiento y evaluar la oferta de cooperación colombiana, hasta el momento no se ha logrado mostrar el ejercicio de evaluación de forma sistemática. El MCAV se diseñó en 2016 con el propósito de "identificar cómo la cooperación que oferta Colombia está contribuyendo al desarrollo de sus países socios". La APC-Colombia determinó que su objetivo iba más allá de la mera identificación de costos o recursos empleados, para poner mayor atención en elementos cualitativos y cuantitativos que le permitieran reconocer el valor de su cooperación a partir de la generación de beneficios tangibles que contribuyan al desarrollo de sus socios.

En este sentido, la APC-Colombia considera relevante identificar las "contribuciones al desarrollo" de cada proyecto

${ }^{15}$ Uribe, ibid. 
de la oferta de cooperación. Esta "agregación de valor", como se ha denominado, se determina en cinco dimensiones: conocimiento, relacional, visibilidad, alineación a los oDs y enfoque diferencial. Cada dimensión tiene un indicador numeral del 1 al 3 con el cual se valora cada una de las dimensiones en cada proyecto. Esta evaluación determina si el proyecto logró o no agregar valor en el país receptor. ${ }^{16}$

Si bien la metodología sugiere que se haga una evaluación conjunta entre Colombia y el socio beneficiario, por ahora la experiencia ha demostrado que hay ciertas reticencias de los países receptores hacia este modelo; se le considera complejo y minucioso y no se tiene claro su funcionamiento y resultados. Asimismo, su aplicación ha sido motivo de cierta controversia sobre todo con países socios que cuentan con una metodología o modelo de medición y/o un formato de proyecto que no necesariamente es coincidente con las categorías que se contemplan en el formato de proyecto de la APCColombia.

$\mathrm{Al}$ respecto, la APC-Colombia reconoce la complejidad del proceso, pero confía en que la metodología, pionera en la región, puede contribuir al fortalecimiento de la css al contar con evidencia sobre los resultados y aportes tangibles que esta modalidad puede traer a los procesos de desarrollo de los países. A la fecha se ha publicado un ejemplo de la aplicación del MCAV en una iniciativa de css entre Colombia y Bolivia, orientada al fortalecimiento de las capacidades productivas del cultivo de la quinua en cuatro municipios del Departamento de Boyacá, Colombia. ${ }^{17}$

${ }^{16}$ Se sugiere ver el Manual de la Caja de Herramientas de la Cooperación Sur-Sur, Colombia, de la APC-Colombia, 2017, apartado 3, https:/ / www.apccolombia.gov.co/sites/default/files/manualcss.pdf

${ }^{17}$ F. Nivia-Ruiz, "La medición de la Cooperación Sur-Sur colombiana a cuarenta años del PABA: Una propuesta de convergencia entre cuantificación y agregación de valor”, Oasis, 31, 2020, pp. 65-68. 
Resultados y efectividad de la css colombiana

\section{Rendición de cuentas y transparencia}

Desde finales de los años noventa, Colombia ha intentado poner en marcha diversos ejercicios de rendición de cuentas sobre su cooperación, tanto la que recibe como la que oferta. No obstante, no ha sido hasta 2004 que, con el apoyo financiero de la Unión Europea, la Dirección de Cooperación Internacional de Acción Social creó una base de datos sobre la cooperación, denominado Sistema de Información de Ayuda Oficial al Desarrollo (SIAOD), para poner a disposición de la sociedad la información relativa a la recepción de cooperación. En 2005, este sistema se complementó con una versión georreferenciada de la cooperación, con el diseño de un "mapa de cooperación" cuyo propósito es establecer el registro, la compilación, el seguimiento y la divulgación de la información correspondiente a la cooperación internacional oficial.

El mapa de cooperación no sólo mostraba los proyectos de cooperación que recibía el país, sino también se incluían las acciones y proyectos de oferta de cooperación, señalando los países socios y proporcionando información general de cada iniciativa. Esta herramienta fue un ejercicio pionero de rendición de cuentas en la región de América Latina que le permitió al gobierno de Colombia mejorar los canales de diálogo y de intercambio de información y coordinación con los donantes, contar con más y mejor información para planear y tomar decisiones, apoyar la gestión, monitoreo y seguimiento de la cooperación, y permitir el acceso público a la información. ${ }^{18}$ Aunque tal iniciativa se presentó como una buena práctica en el Seminario de Cooperación Sur-Sur en

${ }^{18}$ C. Tassara, "La cooperación Sur-Sur de Colombia entre liderazgo y desafíos", en Elías Said Hung (ed.), Cooperación, comunicación y sociedad. Escenarios europeos y latinoamericanos, Barranquilla, Editorial Universidad del Norte, 2013, pp. 1-66. 
Chile, en 2007, el mapa de cooperación dejó de estar en función desde 2016.

Por otro lado, desde 2012 se han publicado informes de gestión y rendición de cuentas en forma anual y están disponibles al público en el sitio web de la dependencia. Estos documentos son el instrumento clave mediante los que se provee información sobre la gestión de la entidad y sus resultados, estableciendo la interlocución y el diálogo con los grupos de interés.

Aun cuando la mayoría de los documentos de rendición de cuentas están disponibles al público en el sitio web de la entidad, aún no es posible tener acceso a información clave para el seguimiento y análisis de la cooperación internacional colombiana, como por ejemplo, los proyectos y acciones de cooperación, países socios, sectores, montos y/o modalidades. Ésta es una debilidad institucional que se acompaña de un deficiente sistema de registro de la información. Al respecto, en 2017 se diseñó el Sistema de Información CÍCLOPE, una herramienta con la que se espera revertir este problema de insuficiencia, y que centralizará la información de la gestión de la cooperación colombiana, con el objetivo de "proveer a la Agencia de información oportuna, pertinente, veraz y con criterios de búsqueda amplios para poder soportar la toma de decisiones y la rendición de cuentas de acuerdo con requerimientos específicos y diversos en materia de Cooperación Sur-Sur y Triangular". ${ }^{19}$ Además, CÍCLOPE contará con un geovisor que facilitará la visualización geográfica de los proyectos de cooperación. Una herramienta similar al anterior "mapa de cooperación”. Hasta el momento (2019) CÍCLOPE no está en funcionamiento.

${ }^{19}$ APC-Colombia, 2015, op. cit. 
Efectividad de la cooperación Sur-Sur de Colombia: creación y fortalecimiento de capacidades

Diversa es la literatura que reconoce que la generación y fortalecimiento de capacidades institucionales en beneficio del desarrollo es uno de los principales objetivos sobre los que descansa la css, no obstante, la evidencia al respecto resulta aún escasa lo que dificulta captar de manera tangible la materialización de este objetivo. El estudio de la css de Colombia confirma este juicio.

Actualmente, el funcionamiento y gestión de la oferta de cooperación colombiana concluye una vez que la transferencia del conocimiento y/o la experiencia compartida cumple con las actividades y objetivos programados. No se propone recoger información que permita dar cuenta de si las actividades y los recursos técnicos y monetarios provistos en las iniciativas han generado capacidades en las instituciones receptoras y si éstas, a su vez, tienen un impacto en las políticas de desarrollo del país beneficiario. Esta falta de evidencia respecto a la generación de beneficios tangibles en las instituciones receptoras es un desafío que la APC-Colombia reconoce y que, en los últimos años (2016-2019) ha intentado actuar en consecuencia. Al respecto, el MCAV pretende ser una herramienta que no sólo permita la cuantificación, sino también un mecanismo para acopiar información sobre el fortalecimiento de capacidades y el valor agregado que la oferta Colombia genera en los países en los que coopera.

\section{México}

Ha logrado consolidarse como una referencia entre los países del Sur en materia de cooperación internacional. Varios son los factores que sustentan tal percepción: el progresivo papel de México como oferente de cooperación en países de América Latina y Asia Pacífico; su papel como receptor de ayuda, consolidando una relación de colaboración con los donantes 
tradicionales, lo que le ha permitido ser un actor promotor de la cooperación triangular que crea alianzas estratégicas con organismos multilaterales y algunos países desarrollados; su participación como facilitador de diálogo en foros internacionales ${ }^{20}$ con capacidad para ser puente entre países en desarrollo y países desarrollados, dada su pertenencia a la OCDE, y la consolidación de un marco institucional y normativo de la cooperación internacional mexicana, a partir de un mandato de ley que entró en vigor en 2011.21

\section{Marco normativo e institucional}

La Ley de Cooperación Internacional para el Desarrollo (LCID) nace de la necesidad apremiante de coordinar y gestionar las acciones de cooperación que llevaban a cabo las dependencias de la Administración Pública Federal (APF), así como de posicionar a México frente a las transformaciones de la escena internacional, se trataba de "blindar mediante un marco jurídico a la cooperación mexicana"22 que

${ }^{20} \mathrm{El}$ caso más reciente fue durante su presidencia del G-20 en 20122013, donde tuvo la oportunidad de contribuir a un enfoque de diálogo entre la cooperación Norte-Sur y la Sur-Sur, fortaleciendo los esquemas triangulares de cooperación con el fin de unir esfuerzos para generar capacidades y el clima propicio entre los países en desarrollo y los países desarrollados para promover de manera integral programas que permitan crear fuentes sostenibles de crecimiento económico, así como una mayor y más eficiente movilización de recursos para el desarrollo.

${ }^{21}$ J.O. Tripp y B. Vega, "Asociaciones complementarias: base para el futuro de la Cooperación Sur-Sur y triangular de México", Revista Española de Desarrollo y Cooperación, núm. 28, (primavera-verano de 2011), pp. 29-42. J. Pérez-Pineda, C. Ayala y F. de la O, Diagnóstico sobre la cooperación internacional para el desarrollo en México 2014-2015, México, Instituto Mora, 2015.

22 J. P. Prado, "La cooperación internacional para el desarrollo de México. Un análisis de sus acciones, institucionalización y percepciones", Revista Mexicana de Ciencias Políticas y Sociales, unam, año Lix, núm. 222, septiembre-diciembre de 2014, p. 67. 
garantizara la continuidad de las instituciones creadas evitando que estuvieran sujetas a vaivenes políticos.

De esta forma, desde el Senado de la República de México se formuló en 2007 el proyecto de Ley de CID, bajo disposición de la senadora Rosario Green y tras un "proceso legislativo inusitadamente arduo, tortuoso y largo". ${ }^{23}$ La Ley se aprobó en abril de 2011, representando un hito en la institucionalización de la cooperación mexicana y proveyendo los instrumentos normativos para una política en la materia. La LCID establece los objetivos, principios y lineamientos que buscan asegurar la complementariedad de la cooperación mexicana con los esfuerzos propios de los países, la sostenibilidad de los procesos de desarrollo y la apropiación de los receptores de la oferta de cooperación mexicana, por medio del cofinanciamiento y otros aportes de las diferentes partes involucradas. Su propósito es dotar de mayor institucionalidad a la cooperación mexicana "a través de la conformación de instancias y mecanismos de gestión y financiamiento que resistan los embates propios a los cambios del gobierno federal". ${ }^{24}$

El andamiaje institucional de la cooperación mexicana que emana de la LCID está constituido por cinco pilares: la Agencia Mexicana de Cooperación Internacional para el Desarrollo (Amexcid), que es la institución coordinadora; el Programa de Cooperación Internacional para el Desarrollo (Procid), que es el instrumento programático para la planeación y ejecución de las acciones de cooperación internacional; el Fondo Nacional de Cooperación Internacional para el Desarrollo (Foncid), pilar financiero de la cooperación internacional, el cual está en proceso de revisión para su eliminación en 2020, y el Registro Nacional y Sistema de Información de Cooperación Internacional para el Desarrollo

${ }^{23}$ L. Garzón, "El andamiaje jurídico e institucional de la Ley de Cooperación Internacional para el Desarrollo de México”, Revista Española de Desarrollo y Cooperación, núm. 28 (2011), p. 47. Y Ley de Cooperación Internacional para el Desarrollo, op. cit.

${ }^{24}$ J. P. Prado, La cooperación Sur-Sur de México en el gobierno del presidente Enrique Peña Nieto, 2013-2018, Oxfam-NesT, julio de 2018, p. 182. 
(Rencid y SICID), instrumentos de seguimiento, registro y cuantificación de la cooperación.

En abril de 2014 fue publicado el Decreto por el que se aprobó el Programa de Cooperación Internacional para el Desarrollo 2014-2018, ${ }^{25}$ en el que se establecieron las estrategias y principios rectores de la cooperación mexicana para este periodo, trazando al mismo tiempo las prioridades temáticas y geográficas. El Programa se complementó con las estrategias y líneas de acción derivadas del Plan Nacional de Desarrollo 2013-2018, que guían la política nacional en la materia y la alinean con la agenda de desarrollo internacional. No obstante, el Procid aún necesita una metodología de seguimiento y evaluación a fin de que sea posible conocer el grado de avance alcanzado sobre los mandatos expuestos.

De acuerdo con el artículo $4^{\circ}$ de la LCID, la cooperación horizontal es aquella “...en la que los recursos del oferente son complementados con recursos de contraparte aportados por el receptor"; por su parte, la cooperación triangular es la "modalidad de cooperación en asociación con una fuente tradicional bilateral o multilateral, para concurrir, conjuntamente, en acciones en favor de una tercera nación demandante, de menor o similar desarrollo relativo"; la cooperación vertical "es la que se otorga a países en vías de desarrollo sin aporte de recursos de contraparte"; y, la oferta de cooperación se refiere a "las acciones de cooperación internacional que las instituciones mexicanas pueden realizar en apoyo de terceros países, en las modalidades de cooperación vertical, horizontal y triangular". ${ }^{26}$

El objetivo en materia de cooperación es consolidar una estrategia institucional y de gestión de la css en la región de América Latina y el Caribe, posicionando a México como

${ }^{25}$ Véase documento completo en Gobierno de México, Secretaría de Relaciones Exteriores, Programa de Cooperación Internacional para el Desarrollo 2014-2018, Procid, Diario Oficial de la Federación, 30 de abril de 2014, http://dof.gob.mx/nota_detalle.php?codigo=5342827\&fecha= $30 / 04 / 2014$

${ }^{26}$ Ley de Cooperación Internacional para el Desarrollo, op. cit. 
“cooperante líder por su institucionalidad y gestión, así como por ser un agente articulador de socios comprometidos con el desarrollo a fin de que contribuyan al cumplimiento de la Agenda 2030 mediante esquemas innovadores de asociación multiactor". ${ }^{27}$

Funcionamiento de la CSS mexicana

\section{Planeación y negociación}

Además de contar con el Procid 2014-2018, instrumento de programación de la cooperación mexicana en el cual se enmarcan los objetivos ${ }^{28}$ y líneas de acción de la cooperación mexicana, la Amexcid ha desarrollado una serie de herramientas y procesos que le permiten planear y definir su oferta de cooperación. Uno de ellos es el catálogo de capacidades, desde el cual México "intenta posicionarse como país proveedor ofreciendo a sus socios lo mejor de sus experiencias y cono-

${ }^{27}$ Participación de Sandra Bucio, Directora General Adjunta de Planeación y Evaluación de la Amexcid, en el conversatorio "Balance de la Cooperación Internacional para el Desarrollo de México a cinco años de promulgada la LCID”, en A. Huitrón, G. Sánchez, A. Peña, Reseña del conversatorio "Balance de la Cooperación Internacional para el Desarrollo de México a cinco años de promulgada la LCID", https:/ / www.academia.edu/2 2286476/Rese\%C3\%B1a_Conversatorio_Balance_de_la_Cooperaci\% C3\%B3n_Internacional_para_el_Desarrollo_de_M\%C3\%A9xico_a_ cinco_a\%C3\%B1os_de_promulgada_la_LCID_

${ }^{28}$ De acuerdo con el Procid 2014-2018, los objetivos de la cooperación mexicana son: i) fortalecer los instrumentos, herramientas y capacidades del sistema del cID mexicano para una mejor gestión de la cooperación; ii) ampliar y promover la cooperación internacional para el desarrollo hacia países y regiones estratégicas (Cooperación Sur-Sur y Triangular); iii) mantener relaciones estratégicas con oferentes de cooperación para atraer recursos y capacidades en beneficio nacional, alineándose con las prioridades nacionales; iv) Incrementar la presencia de México en el mundo mediante la promoción de fortalezas y oportunidades. Gobierno de México, Procid, op. cit. 
cimientos en áreas de éxito nacional"; 29 otro más son los formularios de planificación de proyectos, que es la primera pieza de una metodología más amplia que concluye en la evaluación de las iniciativas de cooperación.

Con el propósito de identificar de manera clara y sistemática las fortalezas institucionales de las dependencias e instituciones mexicanas, y con ello procurar la delimitación de la oferta mexicana de cooperación internacional, en 2012 se publicó el Catálogo de Capacidades Mexicanas de Cooperación Internacional para el Desarrollo, el cual requirió cerca de seis meses de trabajo para la codificación y sistematización de 27 instituciones mexicanas. Este catálogo pretende: i) producir un documento de consulta que ilustre sobre las capacidades y potencialidades de diversas instituciones mexicanas en el terreno de la cooperación; ii) construir una herramienta pertinente para la formulación de la política del ramo, así como para su planeación y iii) imprimir mayor visibilidad a las instituciones publicadas y generar con ello mayores oportunidades de vinculación con sus homólogas internacionales. ${ }^{30}$ El catálogo se reeditó en 2018, logrando actualizar y sistematizar el expertise de los recursos humanos mexicanos y alinear esas capacidades a los ods. ${ }^{31}$

De forma adicional, la Amexcid ha creado una herramienta para facilitar, además de la planeación, el monitoreo de sus iniciativas. Se trata del Formato de Presentación de Proyecto y su Instructivo, ${ }^{32}$ que constituyen las unidades básicas del diseño, planeación y ejecución de la cooperación.

${ }^{29}$ Gobierno de México, Secretaría de Relaciones Exteriores, Amexcid, Catálogo de capacidades mexicanas de cooperación internacional para el desarrollo, México, 2012, https://www.gob.mx/cms/uploads/attachment/ file/109702/catalogo-de-capacidades-mexicanas-de-cid-2012.pdf

${ }^{30}$ Loc.cit.

31 Véase Gobierno de México, Secretaría de Relaciones Exteriores, Amexcid, Catálogo de capacidades mexicanas, México, 2018, https:/ / capacidades.sre.gob.mx/

32 Gobierno de México, Secretaría de Relaciones Exteriores, Amexcid, Instructivo, op. cit. 
Con esta herramienta se espera que los procesos de planificación permitan el monitoreo y alcanzar los resultados de manera eficaz en tanto que, mediante sus indicadores, guiarán la implementación. Cabe mencionar que antes no se tenía una herramienta de uso general para la cooperación de la APF, sino que cada entidad definía sus propios procesos, resultando en esfuerzos "personales, puntuales e inconsistentes". 33

\section{Monitoreo y evaluación}

En su artículo $12^{\circ}$, la LCID mandata el desarrollo de una "metodología para contabilizar el total de los recursos humanos, financieros y técnicos que el conjunto de los cooperantes mexicanos destina..." a la CID. Este artículo hace referencia a un pilar más del sistema mexicano de cooperación: el Rencid, la plataforma estadística de registro datos y seguimiento de la cooperación mexicana que prevé el artículo $29^{\circ}$ de la LCID. Al respecto, en 2014 la Amexcid definió las directrices de cuantificación, adecuadas al tipo de cooperación que México ofrece. Estas directrices incluyen metodologías para el cálculo de la concesionalidad ${ }^{34}$ de la cooperación financiera y para la valorización de la cooperación técnica ofrecida mediante el intercambio y la transferencia de experiencias y conocimientos de los expertos mexicanos. ${ }^{35}$

33 Entrevistas a funcionarios de la Amexcid, septiembre-noviembre de 2015.

${ }^{34}$ Cálculo del componente de donación, "Concesionalidad", Asociación Internacional de Fomento, Grupo Mundial, https:/ /aif.bancomundial.org/financiamiento/gestion-de-recursos/calculo-del-componen te-de-donacion

35 Gobierno de México, Secretaría de Relaciones Exteriores, Amexcid, 2018, "Cuantificación de la cooperación internacional para el desarrollo de México”, https://infoamexcid.sre.gob.mx/amexcid/ccid2013/ home.html 
Es de resaltar la tarea que la Amexcid ha acometido en los últimos años para lograr un registro consensuado entre todas las entidades de la APF, recogiendo la mayoría de las actividades de cooperación que tienen lugar a nivel gubernamental -sin contar los niveles subnacionales-. En el marco de este registro, para 2018 (última publicación) se han realizado siete ejercicios de levantamiento de información (para los años 2011-2017) que están disponibles en la página web de la Amexcid $^{36}$ en los que se incluyen las actividades que realizan las distintas dependencias de la APF a través de acciones o proyectos de cooperación.

A pesar de los esfuerzos realizados para su funcionamiento, el Rencid todavía tiene serias limitaciones. Por ejemplo, en su función no es posible registrar a más de dos actores participantes en la relación de cooperación, lo cual impide asentar acciones o proyectos triangulares. Las dependencias de la APF, que son las usuarias del Rencid, no han logrado apropiarse del sistema, pues tampoco les resulta "amigable". La información que arroja no es fidedigna debido a que el procedimiento de registro actual, si bien intenta mejorar la calidad de la información, resulta demasiado complejo para las capacidades técnicas de la Amexcid y del conjunto de la APF que tampoco está familiarizada con los conceptos de la cooperación internacional. Y con base en lo dispuesto en la Ley Federal de Transparencia y Acceso a la Información Pública Gubernamental, ${ }^{37}$ esta información debería presentarse en datos abiertos para garantizar la transparencia y rendición de cuentas. Tales carencias afectan la calidad y actualidad de los datos (desfasados al menos dos años) e impiden que se cum-

36 Véase Gobierno de México, Secretaría de Relaciones Exteriores, Amexcid, "Cooperación internacional para el desarrollo otorgada por México en 2015", México, 2015, https://infoamexcid.sre.gob.mx/amexcid/ ccid2015/index.html

${ }^{37}$ Véase el texto vigente de la Ley Federal de Transparencia y Acceso a la Información Pública Gubernamental, 11 de junio de 2002 (última reforma publicada el 14 de julio de 2014), http:/ /inicio.ifai.org.mx/LFTAIPG/LFTAIPG.pdf 
pla con el artículo $32^{\circ}$ de la LCID que prevé lo siguiente: "Las dependencias y entidades de la APF otorgantes o beneficiarias de las acciones de cooperación internacional estarán obligadas a colaborar con la Amexcid en la organización y actualización del sistema de información". 38

Otro elemento que parece tornar complejo el registro y seguimiento de la información es el InfoAmexcid, una plataforma para uso interno de la Amexcid que también registra información sobre los proyectos de CID. Este sistema interno compila la información de las acciones y proyectos de CID y la promoción económica y cultural se ejecuta en coordinación con las representaciones de México en el exterior y las dependencias y entidades de la administración pública federal; tiene un módulo para que las representaciones de México en el exterior registren las oportunidades comerciales y de inversión, y actividades conjuntas con las oficinas de ProMéxico en el exterior. El InfoAmexcid junto con el Rencid forman el Sicid, pero no tienen conexión entre sí, por lo que la información es dispersa y poco precisa, incluso para los funcionarios de la Amexcid.

Como se ha mencionado, la Amexcid ha creado el Formato de Presentación de Proyecto, el cual, de acuerdo con la entidad: "Facilitará su monitoreo y evaluación, lo que a su vez generará información para analizar el desempeño de la cooperación". ${ }^{39}$ Una de las características relevantes para el monitoreo y la evaluación de este formato es que por primera vez incluye indicadores medibles, comprobables y orientados a resultados que permitirán evaluar el avance del proyecto y sus resultados, así como reconocer y valorizar los cambios que se producen en el país socio a partir de la implementación del proyecto. No obstante, este formato se puso en práctica en 2017 y a la fecha (2019) no se conoce información pública sobre su práctica, ni sus resultados.

${ }^{38}$ Ley de Cooperación Internacional para el Desarrollo, op. cit.

39 Gobierno de México, Secretaría de Relaciones Exteriores, Amexcid, Instructivo Amexcid, 2017, op. cit., p. 3. 
Finalmente, en materia de evaluación, en 2015 la Amexcid diseñó una Estrategia de Evaluación 2015-2016 como parte del Sistema de Planeación, Monitoreo y Evaluación que la entidad tiene planeado consolidar, y cuyo objetivo es desarrollar herramientas metodológicas para mejorar el diseño de proyectos, facilitar su seguimiento y generar evidencia sobre los resultados de la cooperación que nutra el proceso de aprendizaje institucional, Así, en 2015 se realizó la Evaluación de Programas de Cooperación Técnica y Científica entre México y Honduras (2011-2015) ${ }^{40}$ como el primer ejercicio de este tipo, cuyo objetivo fue analizar los procesos de gestión, calidad de servicios y productos, así como la pertinencia y resultados de la cooperación mexicana brindada. Amexcid preveía realizar dos ejercicios piloto más: uno enfocado en la cooperación brindada por el Consejo Nacional de Evaluación de la Política de Desarrollo Social (Coneval) y otro más en la cooperación bilateral México-El Salvador, pero éstos no se han publicado. Aun con este esfuerzo, la Amexcid continúa los trabajos en esta materia para lograr contar con una metodología de evaluación de su cooperación Sur-Sur.

\section{Resultados y efectividad de la css de México}

\section{Rendición de cuentas y transparencia}

Desde 2014, en el portal de la Amexcid ${ }^{41}$ se publican los ejercicios de cuantificación como resultado de la metodología actual correspondiente, aplicada a los ejercicios de 2011-2018 (último a la fecha). Esta información se publica de manera agregada sin tener acceso abierto a la información desagrega-

40 Véase documento en Gobierno de México, Secretaría de Relaciones Exteriores, Amexcid, "Evaluación de los programas de cooperación técnica y científica México-Honduras, 2011-2015”, México, sPI, https:// www.gob.mx/cms/uploads/attachment/file/277698/Cooperaci_n_tec nica_Mexico-Honduras.pdf

${ }^{41}$ Véase Amexcid, 2018, op. cit. 
da. De manera particular, es posible a acceder a información más detallada a través de solicitudes personales a funcionarios de la Amexcid o al Instituto Nacional de Acceso a la Información (INAI). Todo ello otorga cierta discrecionalidad al acceso a la información de la CID mexicana, ya que la provisión de datos depende del funcionario al que se le haga la solicitud y de quién sea la persona que la solicite. Esto es contrario a los mandatos de la LCID, cuyos artículos, $1^{\circ}$ y $19^{\circ}$ (fracción XII) se refieren a la obligación de Amexcid de "proporcionar la información, los datos, criterios de calificación o de la cooperación técnica que le sea requerida oficialmente, de conformidad con lo dispuesto en esta Ley y de lo establecido en la Ley Federal de Transparencia y Acceso a la Información Pública Gubernamental". ${ }^{42}$

Lo anterior muestra que, a pesar del marco jurídico, normativo e institucional que sostiene la práctica de la cooperación mexicana, todavía no se ha logrado consolidar una política de cooperación en la que se integren plenamente las tareas de transparencia y rendición de cuentas.

Efectividad de la css de México: creación y fortalecimiento de capacidades

Si bien la cooperación técnica y científica no es la que ocupa el lugar más destacado en lo que respecta a la movilización de recursos de la cooperación mexicana, su relevancia está dada por el alto número de proyectos y programas de intercambio de conocimiento, experiencias y tecnología. Mediante el intercambio técnico se busca "el fortalecimiento de capacidades institucionales de países en desarrollo". ${ }^{43}$ En el diseño y gestión de los proyectos de las entidades mexicanas y sus contrapartes se pretende que las asistencias técnicas permanezcan en el tiempo a través de la generación de pro-

${ }^{42}$ Ley de Cooperación Internacional para el Desarrollo, op. cit.

43 Gobierno de México, sre, Procid, op. cit. 
tocolos, manuales, mejora de lineamientos e instrumentos de operación, ${ }^{44}$ entre otros, esperando que estos productos mejoren la calidad de los procesos y promuevan políticas públicas en beneficio de la población. No obstante, lo anterior está aún sujeto al reto de dar continuidad y seguimiento a los proyectos en una fase posterior a su implementación como parte de la sostenibilidad.

Un ejemplo de esto es el que se observa en el "Programa de Cooperación Técnica para el Fortalecimiento de Capacidades para el Monitoreo, Protocolos y Alertas por Amenazas de la Contaminación del Aire de San Salvador 2014-2016”, proyecto en el que se desarrolló el documento "Índices y protocolos para la emisión de Boletines de Alerta por mala calidad del aire urbano en el AMss y su relación con la salud", teniendo un impacto real en la mejora de la generación de datos y análisis en beneficio de la población. ${ }^{45}$

Tal evidencia muestra la efectividad de la cooperación mexicana para generar capacidades locales. No obstante, se reconoce que existe una falta de mecanismos, procesos e instrumentos institucionales y sistematizados en el proceso de implementación de la cooperación mexicana que garanticen evaluar la generación de capacidades, así como la sostenibilidad de los proyectos implementados. De no lograr superar este desafío se pone en riesgo el alcance de los objetivos de la cooperación mexicana de "contribuir al desarrollo de las regiones prioritarias y consolidarse como un actor con responsabilidad global". ${ }^{46}$

44 Véase el proyecto "Técnicas de Espectroscopia óptica para la detección de estupefacientes y sustancias peligrosas" que tuvo como resultado el desarrollo de una herramienta tecnológica (plataforma de datos, metodología, protocolos y manuales) que permite la revisión no invasiva de paquetes y objetos para la identificación de sustancias peligrosas y estupefacientes, A. Huitrón, O. Garelli y N. Besharati, La cooperación México-El Salvador, entre su institucionalidad y sus desafíos operativos, México, Oxfam, 2016.

${ }^{45}$ Loc. cit.

46 Amexcid, Procid, op. cit. 


\section{Contrastando los PRINGipios de la CSS: ESTUdio COMPARADO}

Una vez estudiadas las principales características de los marcos normativos y de gestión sobre los que descansa la práctica de la css de las experiencias revisadas, en este último apartado se pretende contrastar los elementos doctrinales que se le atribuyen a la css en esas realidades, mostrando la presencia de los principios propios de esta modalidad de cooperación: implicación nacional, pertinencia, reciprocidad y horizontalidad. De manera resumida, en el cuadro 1 se muestra evidencia en cada uno de los casos que permite contrastar dicha presencia.

\section{Cuadro 1 \\ Contrastando los principios de}

\begin{tabular}{|c|c|}
\hline Colombia & México \\
\hline \multicolumn{2}{|c|}{ Implicación nacional } \\
\hline $\begin{array}{l}\text { - En el contexto de la css bilateral, Colom- } \\
\text { bia planifica su cooperación a través del } \\
\text { mecanismo de las Comisiones Mixtas, que } \\
\text { coadyuvan a establecer una relación de colabo- } \\
\text { ración basada en la demanda de los países } \\
\text { beneficiarios bajo el diálogo y consenso. } \\
\text { APc-Colombia estimula la participación de } \\
\text { actores sectoriales y no estatales en el diseño } \\
\text { y negociación de los proyectos, gracias a una } \\
\text { coordinación interinstitucional entre la } \\
\text { Dirección de Coordinación Interinstitu- } \\
\text { cional (DCI), encargada de la interacción } \\
\text { con estos actores, y la Dirección de Ofer- } \\
\text { ta de la agencia. Esto facilita la identifi- } \\
\text { cación de capacidades para responder a } \\
\text { las demandas de los países socios, además } \\
\text { de establecer el contacto directo entre } \\
\text { ejecutores y beneficiarios, garantizando su } \\
\text { vinculación en el proceso. }\end{array}$ & $\begin{array}{l}\text { - La Amexcid establece las relaciones de } \\
\text { cooperación con los países socios a través } \\
\text { de Comisiones Mixtas (Comixtas), en las } \\
\text { que, mediante el diálogo y el acuerdo entre las } \\
\text { partes, se definen y aprueban los sectores } \\
\text { prioritarios y los proyectos de cooperación } \\
\text { que se ejecutarán durante un plazo de dos } \\
\text { años. } \\
\text { - Los Fondos Conjuntos de Cooperación } \\
\text { (con Chile y Uruguay), destinan recursos } \\
\text { para la implementación de proyectos diseña- } \\
\text { dos y solicitados por las instituciones del país } \\
\text { demandante. } \\
\text { - Pese a que se pretende conducir una css } \\
\text { alineada a la demanda y promotora del } \\
\text { liderazgo del demandante, existen accio- } \\
\text { nes que, en ocasiones, se emprenden de ma- } \\
\text { nera unilateral (iniciativas coyunturales } \\
\text { determinadas por intereses puntuales e } \\
\text { inmediatos) y omiten los elementos que han } \\
\text { de guiar la práctica de la css. }\end{array}$ \\
\hline
\end{tabular}




\section{Pertinencia}

- APC-Colombia cuenta con el formulario de proyecto, la unidad clave de la "caja de herramientas" de la css, que ayuda a identificar si los proyectos se encuentran alineados a las prioridades de desarrollo nacional y si contribuye al logro de la Agenda 2030 y a cuál de los oDs específicamente.

- APG-Colombia en 2016 puso en marcha "Saber hacer Colombia", una herramienta de sistematización de experiencias de desarrollo exitosas, que tiene el objetivo de visibilizar el abanico de experiencias y capacidades de Colombia. Mediante la documentación de estos aprendizajes y buenas prácticas, se ha construido el portafolio de oferta de capacidades de Colombia.
- Las Comixtas facilitan que los países demandantes formulen y presenten sus propuestas de proyectos de acuerdo con sus necesidades, que revisa México como socio oferente para reconocer si las capacidades con las que cuenta el país permiten responder a la solicitud planteada.

- Una vez reconocidas las demandas y capacidades de los países socios se aprueban de manera conjunta los proyectos y se programa su ejecución.

\section{Reciprocidad}

- La APC-Colombia aspira a que el total de sus actividades e iniciativas de cooperación se realice bajo esquemas de "doble vía", donde los costos y los beneficios se comparten y cuya lógica descansa en que todos los países tienen algo que aportar y algo que aprender, rompiendo con "esquemas verticales de cooperación de una sola vía".

- De acuerdo con la APC-Colombia, las intervenciones deben identificar el trabajo y responsabilidades compartidas y un beneficio mutuo a través de una comunicación basada en la confianza y el respeto a la soberanía del país socio.

- Si bien este espíritu de reciprocidad se observa con mayor frecuencia en los esquemas de cooperación con América Latina, en colaboraciones con el Caribe o con países de África o Asia, este principio no se logra materializar. La mayoría de la oferta de cooperación con estos países se da en esquemas más verticales y el liderazgo, tanto en la ejecución como en los costos, lo asume Colombia como país oferente.
- México ha establecido entre sus lineamientos de operación realizar su css bajo el esquema de costos compartidos. Esto afecta a las actividades de cooperación que impliquen el envío de personal, en las cuales los costos de transporte internacional se sufragan por el país que ofrece la cooperación o el intercambio de experiencias, mientras que el costo de hospedaje, alimentación y transporte local es cubierto por la parte beneficiaria. Este lineamiento se sigue en los casos en los que los países socios cuentan con la capacidad financiera de cubrir estos costos, pero es flexible con socios con recursos limitados.

- En cuanto al criterio de beneficio mutuo, si bien son los países beneficiarios los que rentabilizan el beneficio directo y explícito de la oferta, México también obtiene rédito de su oferta, al menos en un doble sentido. Por una parte, el intercambio de experiencia favorece el aprendizaje técnico, que a su vez tiene impactos en la mejora de procesos 
- Las evaluaciones conjuntas eran un mecanismo casi inexistente en las acciones o proyectos de oferta de cooperación de Colombia. Es a partir de la "metodología de agregación de valor" que se pretende realizar evaluaciones entre las partes, tanto durante la implementación de cada proyecto como al final. Pero aún se trata de un propósito más que una realidad ya tangible. internos; por otra, encuentra beneficios "al posicionar al país en el ámbito internacional". ${ }^{a}$

\section{Horizontalidad}

- Colombia concibe la horizontalidad como ámbitos de trabajo donde prime el diálogo entre las partes, la transparencia, no haya condicionalidad ni cooperación ligada, y se establezcan lazos de confianza mutua. Bajo esta concepción, la cooperación colombiana "se gestiona y ejecuta desde la convicción de realizar un trabajo entre 'iguales' en la que prime, pese a las diferencias de ingreso, el respeto a las demandas de cooperación que cada país establezca de acuerdo con sus prioridades, políticas y procesos de desarrollo, así como el respeto a la soberanía y autonomía política de cada país proveyendo una cooperación no asistencialista ni atada”.

- No se observa que haya condicionalidad explícita alguna, sin embargo, "la oferta de cooperación responde a unos intereses legítimos de la política exterior del país [...], como se observa en la cooperación con el Caribe, por ejemplo, en donde hay intereses 'legítimos' en contar con la colaboración del Caricom en la esfera internacional". b
- La cooperación mexicana reconoce la horizontalidad como un principio básico de la css, estableciendo que "los países colaboran entre sí en términos de socios, de manera voluntaria y sin el establecimiento de condiciones". En este sentido, la cooperación mexicana asume como principio rector de su práctica la no condicionalidad que pudieran cuestionar el trato entre iguales ni la soberanía nacional del país beneficiario.

- Se establece que "la ejecución de una acción de cSS debe haber sido sometida a consenso por los responsables de cada país en marcos de negociación común", d siendo las comisiones mixtas, una vez más, el espacio de diálogo donde, en forma conjunta, se definen los objetivos y proyectos de cooperación.

- El principio de horizontalidad no es exclusivo de la relación de cooperación bilateral y/o de las comisiones mixtas, también se encuentra en mecanismos de cooperación regional, como el Proyecto Mesoamérica y plataformas regionales de diálogo político, estando por tanto presente en el conjunto de la oferta de cooperación mexicana.

Fuente: elaboración propia.

a Entrevista a funcionario de Amexcid, septiembre de 2015.

b Entrevista con funcionario de la APC-Colombia, octubre de 2016.

c Procid, op. cit.

d Loc. cit. 
Hacer un análisis detenido de la política de cooperación de Colombia y México permite sugerir que en los marcos normativos y legales (para el caso de México), así como en algunos procesos de gestión y coordinación de la cooperación internacional, estos países incorporan los preceptos doctrinales que se identifican como propios de la css. No obstante, no todos se aplican con la misma consistencia.

En el caso de la cooperación de Colombia, se ha manifestado la intención de "hacer una cooperación que rompa con esquemas verticales de cooperación y de una sola vía", en favor de una mayor reciprocidad. Sin embargo, la reciprocidad financiera no se logra materializar, sobre todo con países de América Latina con menor renta o con países de Asia y África, encontrándose que la mayoría de la oferta de cooperación de Colombia con éstos se da en esquemas más verticales -de oferente a receptor-y el liderazgo, tanto en la ejecución como en los costos, lo suele asumir Colombia como país oferente. Asimismo, es de señalar que las evaluaciones conjuntas son un mecanismo casi inexistente en las acciones o proyectos de oferta de cooperación de Colombia aunque, a partir de la metodología de agregación de valor, se espera que las evaluaciones conjuntas sean parte de un proceso institucionalizado. Por otro lado, en la cooperación colombiana no existen procesos de acompañamiento posterior a la ejecución del proyecto que garanticen de algún modo la sostenibilidad de los resultados.

Por su parte, en la cooperación mexicana, si bien en el Procid 2014-2018 la cooperación internacional de México recoge los principios que se establecieron en el Documento Final del FAN IV de Busan, de 2011, para regir la ciD de México: apropiación y alineación; armonización; gestión orientada a resultados; mutua responsabilidad; transparencia y rendición de cuentas; perspectiva de género; derechos humanos; inclusión; complementariedad; sostenibilidad y, financiamiento conjunto, se observa que no todos se cumplen de la misma manera. En cuanto a costos compartidos, la reciprocidad se aplica con mayor frecuencia en colaboraciones con países de 
un nivel de renta igual o similar que México. Por el contrario, en colaboraciones con países de niveles inferiores de renta este esquema es menos usual, como se observa en las relaciones de cooperación con países de Centroamérica, donde México asume la mayor parte de los costos financieros.

Para tener una visión amplia del análisis comparado entre los casos se presenta el cuadro 2 en donde, con la herramienta de valoración cualitativa y su interpretación mediante un "semáforo", se puede observar la presencia o debilidad de los principios de la css en cada uno de los casos analizados. 


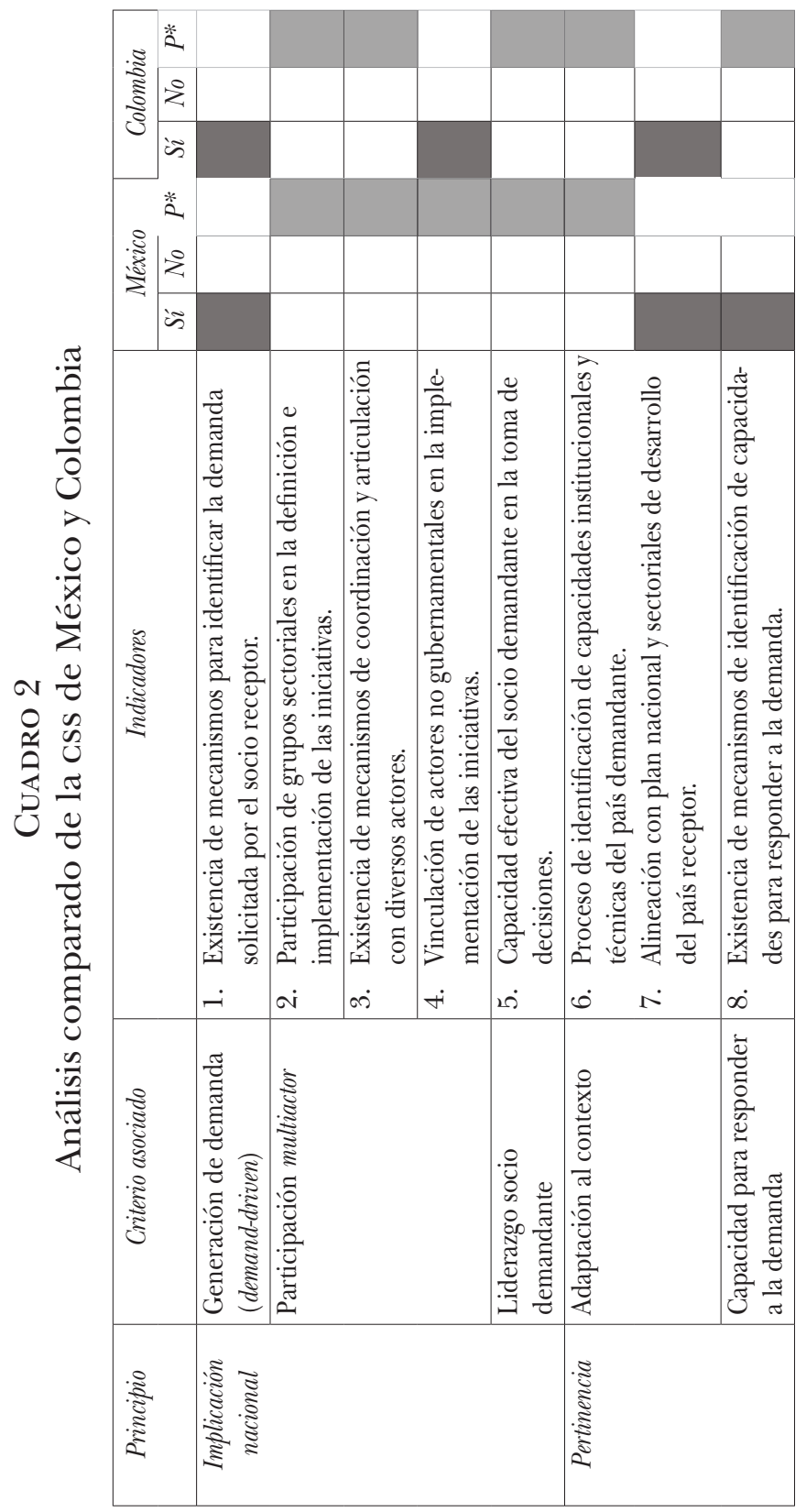




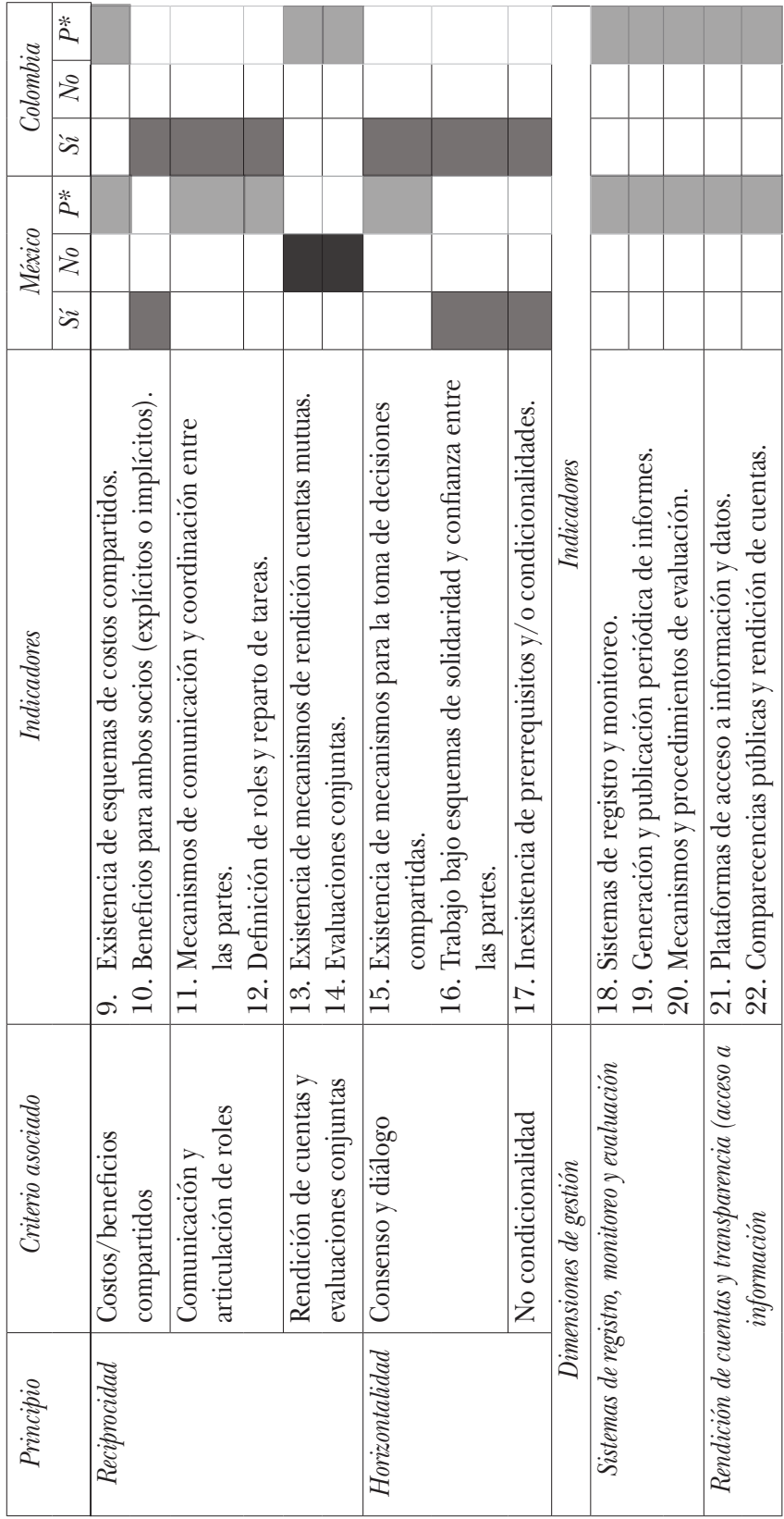




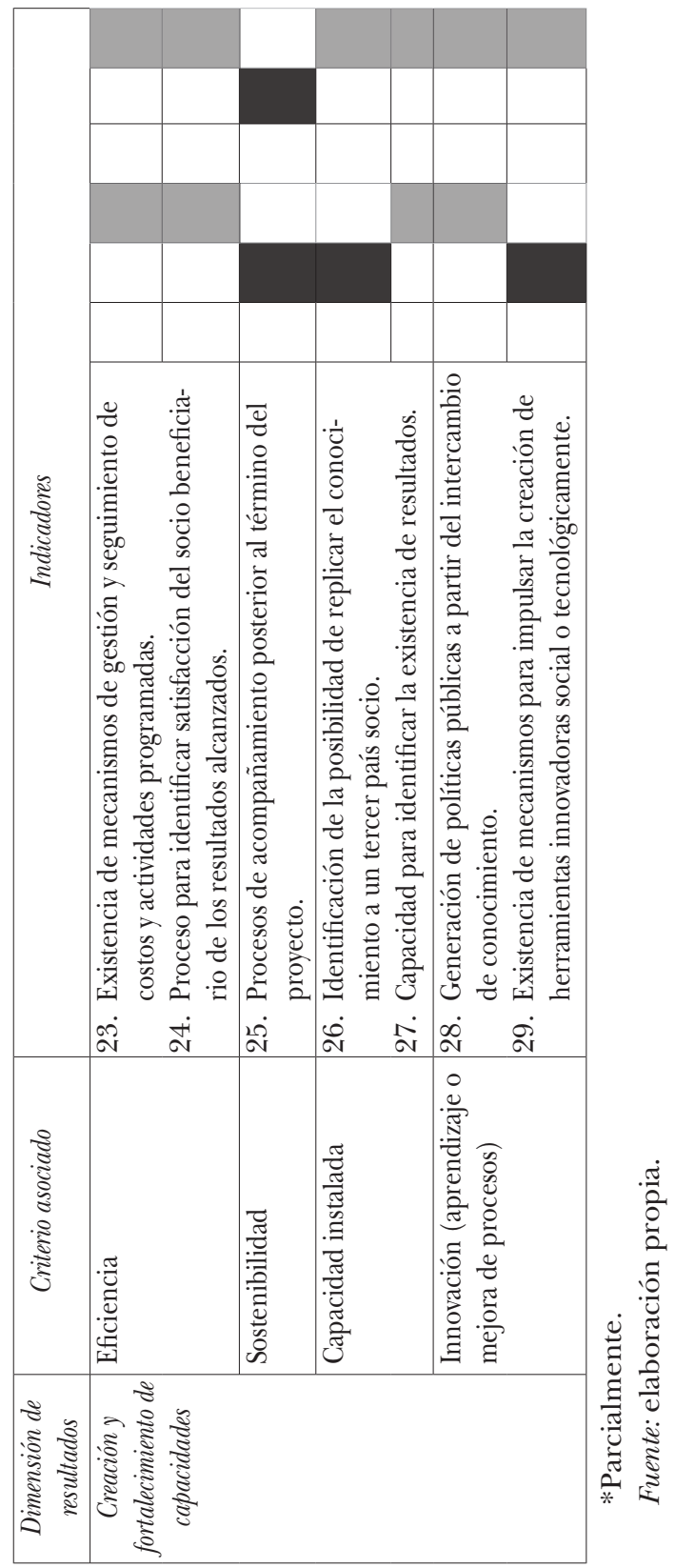




\section{Conclusiones}

Una vez analizada la política de cooperación en dos casos de estudio y contrastado la presencia de los principios que han de guiar la práctica de su css, la conclusión principal es que, pese a que los marcos normativos y/o jurídicos de ambos países adoptan los elementos discursivos de la css, aún no logran que éstos se vean reflejados plenamente en sus mecanismos y procesos de gestión. Ello nos lleva a afirmar que ni todos los principios de la css se aplican en la misma medida, ni todos los países adoptan con igual consistencia esos principios en sus políticas de cooperación.

De manera particular, se observan ciertos desafíos que han de superarse en la medida en que tanto los países estudiados como los países del Sur que practican esta modalidad de cooperación logren hacer una cooperación efectiva y alineada a los principios propios de la css.

En el caso de Colombia se percibe, en primer lugar, una relativa debilidad de los sistemas de información que adolece, por un lado, de un débil proceso de coordinación con los diferentes actores que ofertan y ejecutan la cooperación, así como de una carencia de las herramientas que permitan la centralización, organización y visibilidad de las acciones de cooperación de manera amplia, potenciando la transparencia, rendición de cuentas y el acceso a la información, proveyendo al conjunto de actores de la sociedad las herramientas necesarias para dar cuenta de la utilidad y los beneficios de los recursos que moviliza y aporta Colombia al sistema de cooperación.

Un desafío adicional que se observa en el caso colombiano tiene que ver con la coyuntura interna de construcción de paz, un proceso frágil que demanda la creatividad e innovación para adaptar los distintos mecanismos, instrumentos y modalidades de la cooperación a fin de que ésta coadyuve de manera eficaz en la consolidación del proceso interno, pero también en la consecución de la paz regional e internacional como un bien público y uno de los objetivos 
globales que se incluye en la Agenda 2030 para el Desarrollo Sostenible. En este contexto se puede prever una reducción de recursos nacionales destinados al Focai, por lo que será necesario innovar en mecanismos de financiación alternativos al Fondo, impulsando con mayor ímpetu esquemas de financiamiento conjunto como, ya se estima, puede ser la cooperación de "doble vía", fortalecer la cooperación triangular y/o motivar fondos Sur-Sur como el Fondo Conjunto México-Chile, por ejemplo.

Un tercer desafío tiene que ver con la relevancia de poner en marcha el Modelo de Agregación de Valor, no sólo para tener evidencia de la contribución de la cooperación colombiana, sobre todo para contar con mecanismos institucionalizados que permitan una evaluación conjunta entre las partes, pudiendo planificar un acompanamiento posterior y/o los mecanismos necesarios para asegurar la sostenibilidad de los resultados.

En el caso de la cooperación mexicana, el primer desafío que se observa es el de dar continuidad al fortalecimiento de la Amexcid -como la institución coordinadora y ejecutora de la cooperación mexicana- a fin de cumplir con sus propósitos clave. El primero de éstos es lograr que su estructura y consolidación institucional le permita ejecutar y cumplir de manera eficiente los mandatos que dispone la LCID, tarea aún pendiente. Un segundo propósito descansa en la construcción de un diálogo tanto con cancillería como con la Secretaría de Hacienda para establecer las prioridades de cooperación internacional en materia de política exterior, así como un presupuesto destinado a la cooperación, poniendo en marcha el Foncid, uno de los pilares del andamiaje institucional señalado en la LCID desde 2011.

Un segundo desafío tiene que ver con identificar el valor agregado de la cooperación mexicana más allá de su cuantificación. Se deben acelerar los estudios de caso y evaluaciones de proyecto a fin de conocer qué resultados se están logrando a partir de las acciones de oferta de cooperación de México. De la mano se identifica el tercer desafío, 
relacionado con mejorar los mecanismos de rendición de cuentas y acceso a la información de la cooperación mexicana. Si bien en el sitio web de la Amexcid hay información agregada de los montos y proyectos de la oferta de cooperación de México, no es información abierta al público ni se generan informes periódicos -el primero y último se publicó en 2011-, además de no ser consistentes con la información que se publica, ${ }^{47}$ lo que impide al público general e interesado hacer un seguimiento oportuno de la actividad de cooperación.

Un cuarto desafío versa sobre la responsabilidad de México de adoptar una posición firme y clara sobre el papel que quiere tener como proveedor de desarrollo. En el marco de una agenda global de desarrollo que demanda un compromiso de todos los países y no sólo de los desarrollados, como país de renta media y miembro de diferentes organismos del sistema de cooperación internacional -G-20, ocDE, G-7, entre otros- México debe asumir responsabilidades diferenciadas en la agenda de la cooperación para el desarrollo, tal como dispone en el artículo $14^{\circ}$ de la Declaración de Busan (2011), iniciativa con la que México se ha comprometido.

\section{REFERENCIAS BIBLIOGRÁFICAS}

Agencia Presidencial de Cooperación Internacional de Colombia, APC, Acuerdo núm. 04 de 7 de marzo de 2012, por el cual se adopta el reglamento del Fondo de Cooperación y Asistencia Internacional, Focai, Colombia, https://www.apccolombia. gov.co/sites/default/files/archivos_usuario/normograma_20 17/acu04mar7_2012_1.pdf

Agencia Presidencial de Cooperación Internacional de Colombia, APC, Presentación Rendición de Cuentas, APC-Colombia, 2015, http://www.apccolombia.gov.co/sites/default/files/archi-

${ }^{47}$ J. P. Prado, La cooperación Sur-Sur de México en el gobierno del presidente Enrique Peña Nieto, 2013-2018, Oxfam-NesT, julio de 2018. 
vos_usuario/2016/presentacion-rendicion-de-cuentas-apc-co lombia-2015.pdf

Agencia Presidencial de Cooperación Internacional de Colombia, APC, Manual. Caja de herramientas de la cooperación Sur-Sur, Bogotá, 2017, https://www.apccolombia.gov.co/sites/default/fi les/manualcss.pdf

Besharati, N., C. Rawhani y O. Garelli Rios, A Monitoring And Evaluation Framework For South-South Sudáfrica, Johanesburgo, NeST Africa-SAIIA, 2017, https:/ /saiia.org.za/research/a-moni toring-and-evaluation-framework-for-south-south-cooperation

BRICS y South-South Cooperation Research and Policy Centre (Articulação SUL), Paths for Developing South-South Cooperation Monitoring and Evaluation Systems, Río de Janeiro, BRICS Policy Center, 2017.

Cálculo del componente de donación, "Concesionalidad", Asociación Internacional de Fomento, Grupo Mundial, https:// aif.bancomundial.org/financiamiento/gestion-de-recursos/ calculo-del-componente-de-donacion

Garzón, L., "El andamiaje jurídico e institucional de la Ley de Cooperación Internacional para el Desarrollo de México”, Revista Española de Desarrollo y Cooperación, núm. 28, Instituto Universitario de Desarrollo y Cooperación-Universidad Complutense de Madrid, 2011.

Gobierno de México, Secretaría de Relaciones Exteriores, Amexcid, Catálogo de Capacidades Mexicanas de Cooperación Internacional para el Desarrollo, México, 2012, https:/ /www.gob.mx/cms/ uploads/attachment/file/109702/catalogo-de-capacidadesmexicanas-de-cid-2012.pdf

Gobierno de México, Secretaría de Relaciones Exteriores, Amexcid, Catálogo de capacidades mexicanas, México, 2018, https:// capacidades.sre.gob.mx/

Gobierno de México, Secretaría de Relaciones Exteriores, Amexcid, "Cooperación internacional para el desarrollo otorgada por México en 2015”, https://infoamexcid.sre.gob.mx/amex$\mathrm{cid} / \mathrm{ccid} 2015 /$ index.html

Gobierno de México, Secretaría de Relaciones Exteriores, Amexcid, 2018, "Cuantificación de la cooperación internacional 
para el desarrollo de México", https://infoamexcid.sre.gob. $\mathrm{mx} /$ amexcid/ccid2013/home.html

Gobierno de México, Secretaría de Relaciones Exteriores, Amexcid, "Evaluación de los programas de cooperación técnica y científica México-Honduras, 2011-2015”, México, sPI, https:/ / www.gob.mx/cms/uploads/attachment/file/277698/ Cooperaci_n_tecnica_Mexico-Honduras.pdf

Gobierno de México, Secretaría de Relaciones Exteriores, Amexcid, Glosario de la Cooperación Internacional Mexicana, México, 2011.

Gobierno de México, Secretaría de Relaciones Exteriores, Amexcid, Informe de Cuantificación de la CID Mexicana 2011-2012, 2011, https://transparencia.sre.gob.mx/amexcid/images/pdf/ transparencia/Informe-cuantifica-CID-AMEXCID-2011-2012. pdf

Gobierno de México, Secretaría de Relaciones Exteriores, Amexcid, Instructivo de Formato de Presentación de Proyecto de Cooperación Internacional para el Desarrollo, 2017, https:// drive.google.com/file/d/0B7Nn7E8FjNTeWFhrcENQM211N $\mathrm{WM} /$ view

Gobierno de México, Secretaría de Relaciones Exteriores, Programa de Cooperación Internacional para el Desarrollo 2014-2018, PROCID, Diario Oficial de la Federación, 30 de abril de 2014, http:// dof.gob.mx/nota_detalle.php?codigo=5342827\&fecha=30/04 $/ 2014$

GuÁqueta, A., "La cooperación técnica en Colombia como una herramienta estratégica de política exterior", Revista Colombia Internacional, núm. 30, 1995, pp. 3-15, https://colombiainter nacional.uniandes.edu.co/view.php/208/1.php

Huitrón, A., "Identidad de la cooperación Sur-Sur y su contribución al sistema internacional de cooperación para el desarrollo. Las experiencias de México, Chile y Colombia”, tesis doctoral, Madrid, Universidad Complutense de Madrid, 2018.

Huitrón, A., "Ecosistemas multiactor en la cooperación Sur-Sur: un prerrequisito para lograr la apropiación nacional", Revista Oasis, Universidad Externado de Colombia, núm. 31, enero-junio de 2020. 
Huitrón, A., "Marco analítico para valorar la cooperación SurSur. Una propuesta desde la academia”, El Trimestre Económico 350, (en prensa), 2021.

Huitrón, A., O. Garelli y N. Besharati, La cooperación México-El Salvador, entre su institucionalidad y sus desafíos operativos, México, Oxfam, 2016.

Huitrón, A., G. SÁnchez, A. Peña, Reseña del conversatorio "Balance de la Cooperación Internacional para el Desarrollo de México a cinco años de promulgada la LCID”, México, Instituto Mora, 2016, https://www.academia.edu/22286476/Rese\%C3 \%B1a_Conversatorio_Balance_de_la_Cooperaci\%C3\%B3n_ Internacional_para_el_Desarrollo_de_M\%C3\%A9xico_a_ cinco_a\%C3\%B1os_de_promulgada_la_LCID_

Ley 318 de 2 de septiembre de 1996, Congreso de Colombia, Diario Oficial núm. 42.884, de 24 de septiembre de 1996.

Ley de Cooperación Internacional para el Desarrollo, Diario Oficial de la Federación, 6 de abril de 2011, última reforma, 6 de noviembre de 2020, http://www.diputados.gob.mx/LeyesBiblio/pdf/LCID_061120.pdf

Ley Federal de Transparencia y Acceso a la Información Pública Gubernamental, 11 de junio de 2002 (última reforma publicada el 14 de julio de 2014), http://inicio.ifai.org.mx/LFTAI PG/LFTAIPG.pdf

Naciones Unidas, Documento final de Nairobi de la Conferencia de Alto Nivel de las Naciones Unidas sobre la Cooperación Sur-Sur, Resolución aprobada por la Asamblea General el 21 de diciembre de 2009, A/RES/64/222/

Naciones Unidas, Conference of Southern Providers South South Cooperation, Issues and Emerging Challenge, DESA/RIS, Nueva Delhi, 15-16 de abril de 2013.

Nivia-Ruiz, F., "La medición de la Cooperación Sur-Sur colombiana a cuarenta años del PABA: Una propuesta de convergencia entre cuantificación y agregación de valor", Oasis, 31, 2020, pp. 51-72.

Pérez-Pineda, J., C. Ayala y F. de la O, Diagnóstico sobre la cooperación internacional para el desarrollo en México 2014-2015, México, Instituto Mora, 2015. 
Programa de Naciones Unidas para el Desarrollo, PNUd, De Londres a Cartagena y a Bogotá. Estrategia de Cooperación Internacional para Colombia, Bogotá, PNUD, 2007, http://www.acnur.org/t3/filead min/Documentos/Publicaciones/2008/6031.pdf?view=1

Prado, J. P., "México. La cooperación Sur-Sur y triangular. El dinamismo vuelto desafío”, en B. Ayllón y T. Ojeda (eds.), La Cooperación Sur-Sur y triangular en América Latina. Políticas afirmativas y prácticas transformadoras, Madrid, IUDC-UCM, 2013, pp. 180-200.

Prado, J. P., "La cooperación internacional para el desarrollo de México. Un análisis de sus acciones, institucionalización y percepciones", Revista Mexicana de Ciencias Politicas y Sociales, UnAm, año LIX, núm. 222, septiembre-diciembre de 2014, pp. 51-86.

Prado, J. P., La cooperación Sur-Sur de México en el gobierno del presidente Enrique Peña Nieto, 2013-2018, México, Oxfam-NesT, julio de 2018, https://www.oxfammexico.org/sites/default/files/ Cooperacion \%20Sur\%20Sur\%20EPN.pdf

Presidencia de la República, Decreto núm. 2467 de 2005, de 21 de julio de 2005, por el cual se fusiona la Agencia Colombiana de Cooperación Internacional, ACCI, a la Red de Solidaridad Social, Rss, y se dictan otras disposiciones, https://www.canci lleria.gov.co/sites/default/files/Normograma/docs/decre to_2467_2005.htm

Secretaría General Iberoamericana, SEgIB, Informe de Cooperación Sur-Sur en Iberoamérica, Madrid, 2007-2017.

Tassara, C., "La cooperación Sur-Sur de Colombia entre liderazgo y desafíos", en Elías Said Hung (ed.), Cooperación, comunicación y sociedad. Escenarios europeos y latinoamericanos, Barranquilla, Editorial Universidad del Norte, 2013, pp. 1-66.

Tassara, C., "South-South Cooperation between Emerging Countries: The Example of Colombia”, en E. Sidiropoulos, J. Pérez y S. Chaturvedi (eds.), Institutional Architecture and Development. Responses from Emerging Powers, Sudáfrica, saiıa, 2015, pp. 115-137.

Tripp, J.O. y B. VegA, “Asociaciones complementarias: base para el futuro de la Cooperación Sur-Sur y triangular de México", Revista Española de Desarrollo y Cooperación, núm. 28, (primaveraverano de 2011), pp. 29-42. 
Uribe, Pablo, "Colombia: Hitos y tendencias como nuevo donante", en Guillermo Santander Campos (coord.), Nuevos Donantes y Cooperación Sur-Sur: estudios de caso, Madrid, Universidad Complutense de Madrid, Instituto Complutense de Estudios Internacionales, 2011, pp. 63-87. 
